Technological University Dublin ARROW@TU Dublin

2010-01-01

\title{
Corrosion Protection Properties of Various Ligand Modified Organic Inorganic Hybrid Coating on AA 2024-T3
}

\author{
Rajath Varma \\ Technological University Dublin, rajath.varma@tudublin.ie \\ John Cassidy \\ Technological University Dublin, john.cassidy@tudublin.ie \\ Mohamed Oubaha \\ Dublin City University, Mohamed.Oubaha@dcu.ie
}

See next page for additional authors

Follow this and additional works at: https://arrow.tudublin.ie/cenresart

Part of the Materials Chemistry Commons

\section{Recommended Citation \\ Varma, R. et al.: Corrosion Protection Properties of Various Ligand Modified Organic Inorganic Hybrid Coating on AA 2024-T3. ECS Transactions, vol. 24 (1), 2010,pp. 231-246. doi:10.1149/1.3453619}

This Article is brought to you for free and open access by the Crest: Centre for Research in Engineering Surface Technology at ARROW@TU Dublin. It has been accepted for inclusion in Articles by an authorized administrator of ARROW@TU Dublin. For more information, please contact arrow.admin@tudublin.ie, aisling.coyne@tudublin.ie,gerard.connolly@tudublin.ie. Funder: Enterprise Ireland CFTD Fund

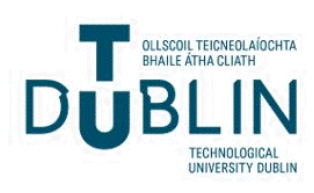




\section{Authors}

Rajath Varma, John Cassidy, Mohamed Oubaha, Colette McDonagh, John Colreavy, and Brendan Duffy

This article is available at ARROW@TU Dublin: https://arrow.tudublin.ie/cenresart/7 


\title{
Corrosion Protection Properties of Various Ligand Modified Organic Inorganic Hybrid Coating on AA 2024-T3
}

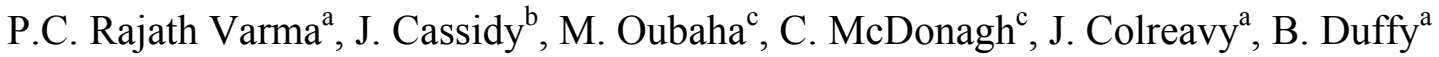 \\ ${ }^{a}$ Centre for Research on Engineering Surface Technology (CREST), FOCAS Institute, \\ Dublin Institute of Technology, 13 Camden Row, Dublin 8, Ireland. \\ ${ }^{\mathrm{b}}$ School of Chemical and Pharmaceutical Sciences, Dublin Institute of Technology, \\ Kevin St., Dublin 8, Ireland. \\ ${ }^{\mathrm{c}}$ National Centre for Sensor Research (NCSR), Dublin City University, Dublin 9, Ireland.
}

The inclusion of zirconium precursors to prepare organosilane solgel coatings improves the corrosion protection performance of the coatings on aluminium and steel. The inherent differences in the hydrolysis rates of the silane and zirconium precursors, various ligands were used to control the hydrolysis by decreasing the number of reactive alkoxide group. Hybrid sols were synthesised using 3-(trimethoxysilyl) propylmethacrylate (MAPTMS) and zirconium n-propoxide chelated with organic ligands including different organic acids, acetyl acetone and 2 2' bipyridyl. The effects of zirconia inclusion on the properties of the coatings were compared on the aerospace alloy AA 2024-T3.

Electrochemical analysis and salt spray exposure characterized the corrosion protective properties. The results indicate that acid chelated systems possess better corrosion protection when compared to the other ligands, due to smaller zirconium nanoparticles being formed. In particular superior performance was displayed by the coatings involving 3,4 diaminobenzoic acid (DABA) due to inherent anticorrosive properties.

\section{Introduction}

Metal alkoxides such as zirconium (IV) propoxide, $\mathrm{Zr}(\mathrm{OR})_{4}$ (TPOZ), react vigorously with water when compared to silicon alkoxides, producing zirconium-oxo/hydroxo precipitates. ${ }^{1}$ This is due to the lower electronegativity of the metal when compared to silicon (silicon is not considered a metal in this context) and coordination number of metal being higher than their valency, which results in coordination expansion. ${ }^{1}$ Metal alkoxides act as Lewis acids, i.e. they can interact with compounds having a lone pair of electrons (Lewis bases) to achieve a higher coordination number ${ }^{1}$. Due to the inherent difference in hydrolysis rate of the metal alkoxide precursors, various bidentate ligands such as acetic acid or acetylacetone have been used in the past to control such alkoxide hydrolysis reactions. ${ }^{2}$ This has proved to be an invaluable technique especially when the gelation stage with competing condensation reactions. ${ }^{3}$ However care must be taken in the substitution of mono dentate alkoxy groups by bi- or multidentate ligands which may lower the connectivity of the molecular building blocks thereby favouring the formation of hydrated gels instead of crystalline precipitates. ${ }^{1}$ Besides controlling the reactivity of the metal alkoxides and the network structure of the obtained gels, the bidentate ligands can also be used to introduce functional organic groups into the materials by means of appropriately substituted derivatives. ${ }^{4}$ For example, when methacrylic acid (containing polymerisable double bonds) is used to replace the metal alkoxide, it coordinates through 
the carboxylate group to the metal and thereby introduces an additional cross-linking functionality to the metal based nanoparticle thereby changing the properties of the final material. The most obvious effect of ligand change is particle size and previous studies which found that the hydrolysis of zirconium alkoxides can be controlled to deliver nanoparticles of varying sizes. ${ }^{5,6}$ More recently Ferreira's group in Portugal have confirmed that the route of zirconium inclusion is important, as the choice of chelating ligand may have an effect of the anticorrosion performance of the final sol-gel coating. ${ }^{7}$ In this work hybrid sols were synthesised using 3-(trimethoxysilyl) propylmethacrylate (MAPTMS) and TPOZ chelated with ligands such as organic acids, acetyl acetone and 2 2 ' bipyridine and were compared with silane coating without zirconium. The inclusion of zirconium enhanced the barrier properties. The results also indicated that the acid ligand modified coatings provided the best corrosion protection when compared to non acid ligands. The ligands used for the study and their structures are given in Fig. 1.

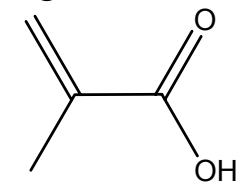

Methacrylic Acid

(MAAH)

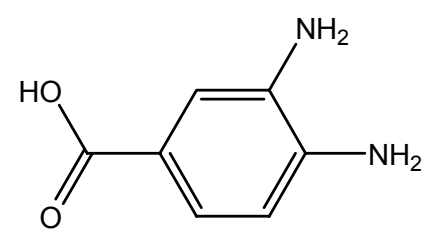

3,4-diaminobenzoic Acid (DABA)

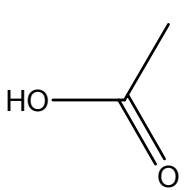

Acetic Acid $(\mathrm{AcOH})$

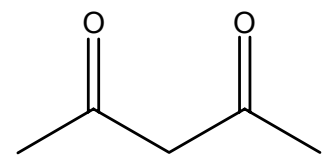

Acetylacetone (acac)

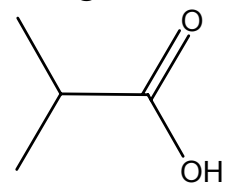

Iso butyric acid (IBA)

Figure 1: Structure of the ligands used to chelate TPOZ

\section{Experimental}

\section{Aluminium panel preparation}

$150 \mathrm{~mm} \times 100 \mathrm{~mm}$ AA2024-T3 aluminium panels (sourced from an industrial partner) were degreased with isopropanol and cleaned using Oakite $61 \mathrm{~B}^{\circledR}$ before being finally rinsed with deionised water and dried. 
Synthesis of Hybrid Sols

The sols were prepared according to the experimental schematic in Fig. 2. The silane precursor, 3-(trimethoxysilyl) propylmethacrylate (MAPTMS) (Sigma Aldrich, Irl, Assay (99\%) was pre-hydrolysed using $0.01 \mathrm{~N} \mathrm{HNO}_{3}$ for 45 min (A). Simultaneously, zirconium (IV) n-propoxide (TPOZ) (Sigma Aldrich, Ireland, Assay $\sim 70 \%$ in propanol) was chelated using one of six ligands, at a 1:1 molar ratio for 45 minutes (B) to form a zirconium complex. All of the ligands (acetic acid, isobutyric acid, methacrylic acid, 3,4 diaminobenzoic acid, acetylacetone and 2,2'-bipyridyl) were purchased from Sigma Aldrich (Ireland). Solution A was slowly added to solution B over ten minutes. Following another $45 \mathrm{~min}$, water ( $\mathrm{pH} 7$ ) was added to this mixture. The molar ratio of $\mathrm{Si} / \mathrm{Zr}$ in the final sol is $4: 1$ and $\mathrm{Si} / \mathrm{H}_{2} \mathrm{O}$ is $1: 2$.

For comparative purposes a MAPTMS sol-gel were prepared by combining silane precursor MAPTMS precursor, dilute $\mathrm{HNO}_{3}$ (aq) as catalyst, ethanol as solvent and water for hydrolysis with a molar ratio of $1 / 0.001 / 2.5 / 5\left(\mathrm{MAPTMS} / \mathrm{HNO}_{3} / \mathrm{ETOH} / \mathrm{H}_{2} \mathrm{O}\right)$. All the reaction mixtures were stirred overnight to complete the reaction. All chemicals were used as received.

The degreased AA2024-T3 panels were flood coated with the sol, before being spun coated at up to $1000 \mathrm{rpm}$ and cured for $12 \mathrm{~h}$ at $100{ }^{\circ} \mathrm{C}$ to form the gel. The controlled coating technique gave a final thickness of $3.5( \pm 0.5) \mu \mathrm{m}$ for all sol-gel coatings, measured using an Isoscope ${ }^{\circledR}$ non-destructive coating thickness gauge. For description purposes the final sol-gel coating materials will be referred in shorthand notation as MAPTMS and for zirconium containing coatings; $\mathrm{Si} / \mathrm{Zr} / \mathrm{Ligand}$ (eg. $\mathrm{Si} / \mathrm{Zr} / \mathrm{AcOH}$ ).

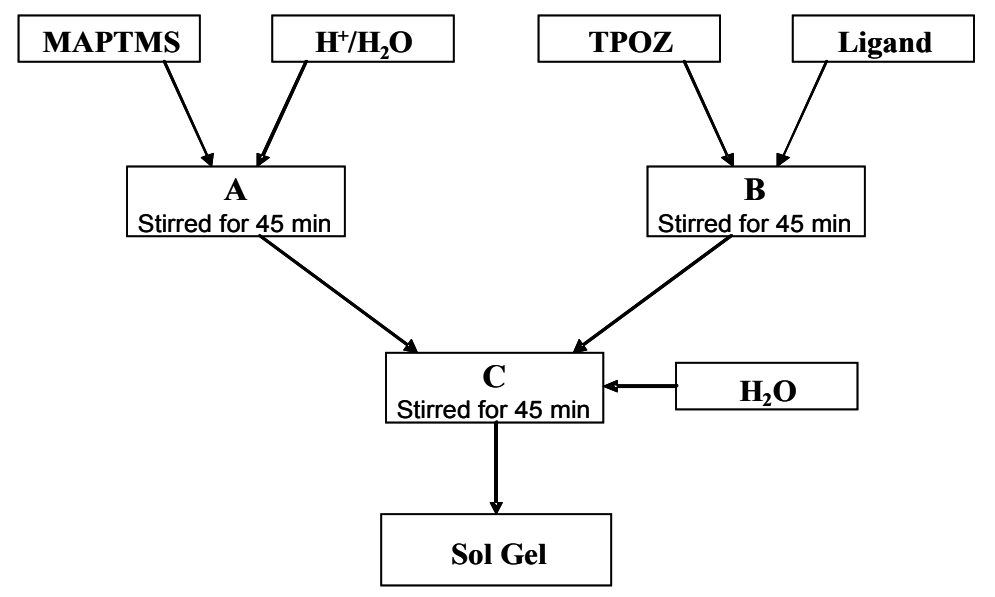

Figure 2: Flow chart for preparation of hybrid sol-gel

\section{Measurements}

Samples for differential scanning calorimetry (DSC) were prepared by dropping $10 \mu 1$ of the sol into a $2 \mathrm{~mm}$ deep aluminium sample pan and curing at $100^{\circ} \mathrm{C}$ for $1 \mathrm{hr}$. Measurements were carried out using a Rheometric Scientific DSC QC instrument under an air atmosphere at a heating rate of $10^{\circ} \mathrm{C} \cdot \mathrm{min}^{-1}$ between $50^{\circ} \mathrm{C}$ and $300^{\circ} \mathrm{C}$.

Sol-gel particle sizes were determined using a Malvern Nano-ZS instrument, using the dynamic light scattering (DLS) technique.

Atomic force microscopy (AFM) studies were acquired using an Asylum MFP-3D $\mathrm{AC} /$ contact mode microscope with a silicon coated aluminium tip. All scans were 
performed at a scan rate of $0.7 \mathrm{~Hz}$. Damage to tip and sample surface were minimized by running the experiment in tapping mode.

Electrochemical impedance spectroscopy (EIS) and potentiodynamic scan (PDS) data was obtained using a Solartron SI 1287/1255B system comprising of a frequency analyser, potentiostat and ZPlot ${ }^{\circledR}$ software. PDS was performed using an electrochemical cell (PAR K0235 Flat Cell) with an exposed area of $0.78 \mathrm{~cm}^{2}$ in an aerated Harrison's solution $\left(3.5 \%(\mathrm{w} / \mathrm{v})\left(\mathrm{NH}_{4}\right)_{2} \mathrm{SO}_{4}\right.$ and $\left.0.5 \%(\mathrm{w} / \mathrm{v}) \mathrm{NaCl}\right)$ where the coated metal acted as working electrode, a silver/silver chloride $(\mathrm{Ag} / \mathrm{AgCl})$ electrode was used as a reference electrode and platinum mesh as counter electrode. All scans were acquired in the region from $-0.8 \mathrm{~V}$ to $+0.8 \mathrm{~V}$ versus the open circuit potential, at a scan rate of $1 \mathrm{mV} / \mathrm{sec}$ at room temperatures $20( \pm 2)^{\circ} \mathrm{C}$. EIS electrochemical cells were made by mounting bottom-less plastic vials to the exposed surface of the coated panel $\left(4.9 \mathrm{~cm}^{2}\right)$ with amine hardened epoxy glue (Araldite ${ }^{\mathbb{R}}$ ). EIS spectra were acquired in the frequency range from $10^{6} \mathrm{~Hz}$ to $10^{-2} \mathrm{~Hz}$ with a modulating potential of $10 \mathrm{mV}$ around the open circuit potential. For the EIS study dilute Harrison's solution $\left(0.35 \%(\mathrm{w} / \mathrm{v})\left(\mathrm{NH}_{4}\right)_{2} \mathrm{SO}_{4}\right.$ and $\left.0.05 \%(\mathrm{w} / \mathrm{v}) \mathrm{NaCl}\right)$ was used as electrolyte.

Accelerated exposure testing of all panels was performed in a salt fog atmosphere generated from a $5 \%(\mathrm{w} / \mathrm{v})$ aqueous $\mathrm{NaCl}$ solution at $35( \pm 1){ }^{\circ} \mathrm{C}$ for up to 168 hours according to ASTM B117 specifications. The non-coated side and the edges of the test panels were protected using a water based polyurethane coating (Alberdink ${ }^{\circledR}$ ). The edges were further protected with insulation tapes to provide a double protection. The panels were assessed according to the ASTM D 1654 standard. To evaluate the scribed area, the test panels were removed from the salt spray cabinet and rinsed with using a gentle stream of water. Then holding the specimen at $45^{\circ}$ angle, air was blown along the scribe. The minimum and maximum creepage from the scribe was noted and panels were rated as described by the standard. A rating of 10 was given to test panel with no creepage from scribe and rating 0 was given to mean creepage $>16 \mathrm{~mm}$ from the scribe. Similarly the unscribed areas of the panels were evaluated and rated as described in the ASTM D 1654 standard.

\section{Result and Discussion}

\section{$\underline{\text { Particle size studies }}$}

Particle size measurements (Table I) give an insight into the influence the organic ligands have on the formation of the zirconium oxide $\left(\mathrm{ZrO}_{2}\right)$ nanoparticles within the silane rich sol prior to coating. The $\mathrm{ZrO}_{2}$ nanoparticles are formed as a result of hydrolysis and condensation of TPOZ as reported in literature. ${ }^{8,9}$ All sol-gel systems are composed of at least two particle distributions. The $\mathrm{ZrO}_{2}$ nanoparticle were seen to form domains in range of 2.5-8.7 $\mathrm{nm}$ typically, while the silane particles are smaller in the range of 0.9-2 $\mathrm{nm}$ due to their lower hydrolytic capability. The smallest particle sizes are MAPTMS/Zr/AcOH, MAPTMS/Zr/MAAH, MAPTMS/Zr/DABA followed by MAPTMS/Zr/acac, MAPTMS/Zr/IBA and finally MAPTMS/Zr/Bipy. Interestingly MAPTMS/Zr/Bipy appears to have formed particles in the $120 \mathrm{~nm}$ range, which may potentially be $\mathrm{Zr}$ /Bipy oligomers. 


\title{
Thermal Stability
}

The thermal stability of silane films is of great industrial importance, as sol-gel films are expected to be used over an wide range of temperatures. DSC analysis was performed on cured sol-gel materials between $50^{\circ} \mathrm{C}$ and $300^{\circ} \mathrm{C}$, although the working temperature for a coating is typically below $250^{\circ} \mathrm{C}$. For a coating to be industrially exploited, $\mathrm{T}_{\mathrm{g}}$ ' $\mathrm{s}$ in excess of $250^{\circ} \mathrm{C}$ are necessary. The results highlight the importance of incorporation of zirconium into the silane network to increase the thermal network stability of the sol-gel coating. The $\mathrm{T}_{g}$ of MAPTMS was found to be lower by a difference of about $130^{\circ} \mathrm{C}$ when compared with some of the coatings with zirconium (see Table I). The results also highlighted that the ligand choice has a profound effect on the $\mathrm{T}_{g}$ of each ligand modified sol-gel coating (Table I). It was found that the $\mathrm{ZrO}_{2}$ nanoparticles formed for MAPTMS/Zr/MAAH and MAPTMS/Zr/AcOH coatings are the most thermally stable $\left(\mathrm{T}_{g}=260{ }^{\circ} \mathrm{C}\right)$, while Bipy $\left(\mathrm{T}_{g}=180{ }^{\circ} \mathrm{C}\right)$ is lowest. This highlights the difference (by up to $80^{\circ} \mathrm{C}$ ) in the ability of the chelating ligand to improve the thermal stability of the sol-gel network. Therefore it is reasonable to infer that the thermal stability of the acid chelated complexes is superior to the weaker basic bonded ligands.

Table I. Physical data for the various sol-gel materials

\begin{tabular}{lcc}
\hline Sol-gel coating & $\mathbf{T}_{g}$ & Particle diameter( \pm 2 d.nm) \\
\hline MAPTMS & 130 & $2.3^{\mathrm{a}}$ \\
MAPTMS/Zr/MAAH & 260 & $0.96^{\mathrm{a}}, 2.6^{\mathrm{b}}$ \\
MAPTMS/Zr/AcOH & 260 & $0.83^{\mathrm{a}}, 7.5^{\mathrm{b}}$ \\
MAPTMS/Zr/IBA & 240 & $1.5^{\mathrm{a}}, 8.7^{\mathrm{b}}$ \\
MAPTMS/Zr/DABA & 230 & $0.9^{\mathrm{a}}, 6.5^{\mathrm{b}}$ \\
MAPTMS/Zr/acac & 206 & $1.17^{\mathrm{a}}, 6.5^{\mathrm{b}}$ \\
MAPTMS/Zr/Bipy & 180 & $2^{\mathrm{a}}, 8.7^{\mathrm{b}}, 122^{\mathrm{c}}$ \\
a Silane sol. & & \\
b Zirconium chelated nanoparticle. & & \\
c Bipy oligomer. & &
\end{tabular}

\begin{abstract}
$\underline{\text { AFM studies }}$
AFM was used for characterizing the surface morphology of all the sol-gel coated AA2024 T3 substrates (Figure 3). The AFM image of the MAPTMS coating (Fig 3 (A)) shows a porous topography with no particles detected. For the other samples, nanoparticles are detected in the coating, which can be attributed to $\mathrm{ZrO}_{2}$ particles formed as a result of hydrolysis and condensation of $\mathrm{TPOZ}^{8}$. MAPTMS/Zr/MAAH, MAPTMS/Zr/AcOH and MAPTMS/Zr/DABA coatings, in Fig. 3, possess relatively uniform particles of size 20-50 nm when cured. In comparison, MAPTMS/Zr/IBA, MAPTMS/Zr/acac and MAPTMS/Zr/Bipy appear to contain several particles with diameters in the 50-100 $\mathrm{nm}$ range, possibly from the agglomerate formation.
\end{abstract}




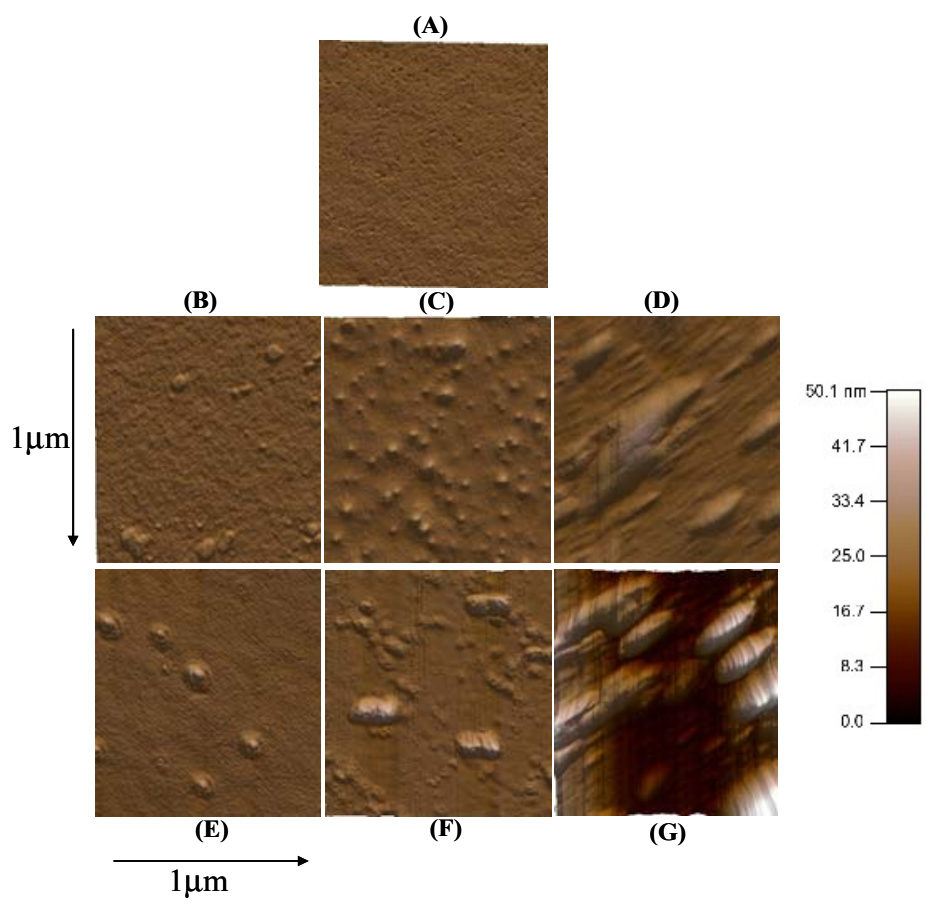

Figure 3: AFM images of different ligand modified hybrid coating before exposure to electrolyte (A)MAPTMS, (B) MAPTMS/Zr/MAAH, (C) MAPTMS/Zr/AcOH, (D) MAPTMS/Zr/IBA, (E) MAPTMS/Zr/DABA, (F) MAPTMS/Zr/acac, (G) MAPTMS/Zr/Bipy.

\section{PDS result}

PDS gives useful information on the properties of thin coatings (less $5 \mu \mathrm{m})$ where properties such as corrosion current density $\left(\mathrm{I}_{\text {corr }}\right)$ and potential $\left(\mathrm{E}_{\text {corr }}\right)$ were estimated by the Tafel method ${ }^{10}$, while the polarisation resistance $\left(\mathrm{R}_{p o l}\right)$ was calculated using SternGeary equation [1]. ${ }^{11}$ Note that as before the solution was not stirred to therefore the readings are of qualitative value only.

$$
I_{\text {corr }}=\frac{B}{R_{p o l}}
$$

The proportionality constant, $\mathrm{B}$, for a particular system can be calculated from $\beta_{\mathrm{a}}$ and $\beta_{\mathrm{c}}$, the slopes of the anodic and cathodic Tafel lines as shown by [2].

$$
B=\frac{\beta_{a} \cdot \beta_{c}}{2.303\left(\beta_{a}+\beta_{c}\right)}
$$

Potentiodynamic scans for MAPTMS/Zr/Ligands modified with different ligands are shown in Fig. 4 and the apparent Tafel parameters such as $\mathrm{I}_{\text {corr }}, \mathrm{E}_{\text {corr }}$ and the Tafel coefficients for all coatings are listed in Table II. The organic acid and acac modified coatings reduced the corrosion current density $\left(\mathrm{I}_{\text {corr }}\right)$ by three orders in magnitude when compared with MAPTMS alone. $\mathrm{ZrO}_{2}$ improves the stability of the coatings due to its ability to consume hydroxide ions at elevated $\mathrm{pH}$, thereby protecting the silane matrix. The beneficial impact of the nanoparticles is observed when comparing the coating resistances $\left(\mathrm{R}_{p o l}\right)$. The coatings modified with MAAH, AcOH, IBA and DABA providing the similar performance with a higher $\mathrm{R}_{p o l}$ by an order of 2 in magnitude when compared 
with acac modified coating, an order of 3 when compared with the basic nitrogen bonding Bipy modified coating and an order of 5 in magnitude when compared with MAPTMS. The hierarchy of performance is in broad agreement with the thermal stability data and confirms that importance of the ligand on the nano particle formation within the silane matrix.

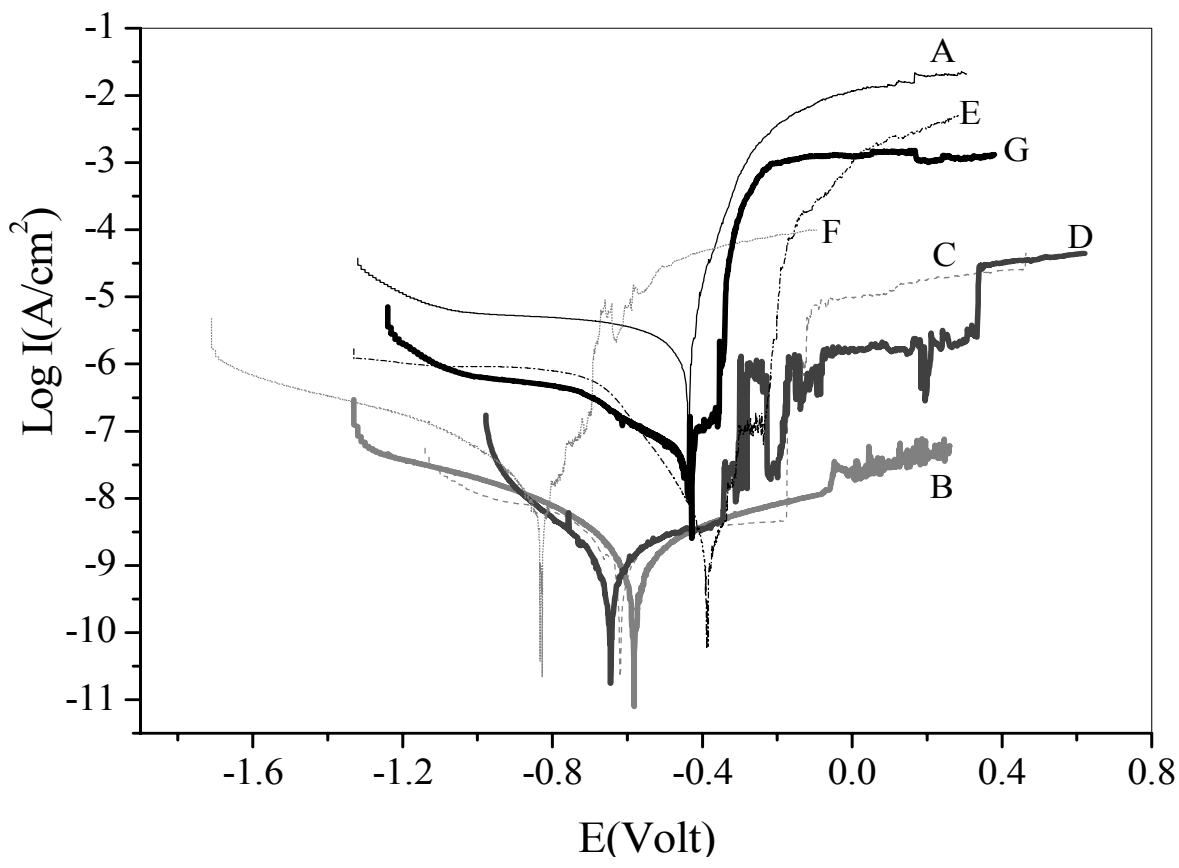

Figure 4. Potentiodynamic curves of sol-gel coatings on AA2024-T3 (A) MAPTMS, (B) MAPTMS/Zr/MAAH, (C) MAPTMS/Zr/AcOH, (D) MAPTMS/Zr/IBA, (E) MAPTMS/Zr/DABA, (F) MAPTMS/Zr/acac, (G) MAPTMS/Zr/Bipy.

\begin{tabular}{|c|c|c|c|c|c|}
\hline Sol-gel coatings & $\begin{array}{c}I_{\text {corr }} \\
\left(\mathbf{A} / \mathbf{c m}^{2}\right)\end{array}$ & $\begin{array}{c}\mathbf{E}_{\text {corr }} \\
\text { (V) }\end{array}$ & $\begin{array}{c}|\boldsymbol{\beta a}| \\
\text { (V/decade) }\end{array}$ & $\begin{array}{c}|\beta c| \\
\text { (V/decade) }\end{array}$ & $\begin{array}{c}\mathbf{R}_{p o l} \\
\left(\Omega . \mathbf{c m}^{2}\right)\end{array}$ \\
\hline MAPTMS & $3.43 \times 10^{-7}$ & -0.450 & 0.023 & 0.005 & $8.51 \times 10^{3}$ \\
\hline MAPTMS/Zr/MAAH & $3.73 \times 10^{-10}$ & -0.581 & 0.124 & 0.058 & $1.28 \times 10^{8}$ \\
\hline MAPTMS/Zr/AcOH & $1.56 \times 10^{-10}$ & -0.619 & 0.057 & 0.079 & $7.62 \times 10^{8}$ \\
\hline MAPTMS/Zr/IBA & $2.48 \times 10^{-10}$ & -0.653 & 0.059 & 0.047 & $4.09 \times 10^{8}$ \\
\hline MAPTMS/Zr/DABA & $5.11 \times 10^{-10}$ & -0.395 & 0.043 & 0.030 & $6.04 \times 10^{7}$ \\
\hline MAPTMS/Zr/acac & $2.59 \times 10^{-10}$ & -0.828 & 0.022 & 0.060 & $5.84 \times 10^{6}$ \\
\hline MAPTMS/Zr/Bipy & $8.68 \times 10^{-8}$ & -0.443 & 0.007 & 0.026 & $8.37 \times 10^{5}$ \\
\hline
\end{tabular}

\section{EIS results}

Electrochemical impedance studies involved applying an AC voltage at the OCP, with sinusoidal amplitude of $10 \mathrm{mV}$, from a frequency of $10^{6} \mathrm{~Hz}$ down to $10^{-2} \mathrm{~Hz}$ across a coating in contact with an aggressive electrolyte. The coatings resistance to the AC signal, or impedance, varies according to the applied frequency and is graphically represented on a Bode frequency plot. The phase angle associated with the impedance gives valuable information on the film properties such as barrier performance and interfacial activity. This activity is often seen as a decrease in coating resistance to a point where oxide begin to dominate the measurements. Primarily EIS will be used as a tool for comparing the physical performance of the coatings. The technique can be modelled as an equivalent electrical circuit composed of resistors and capacitors as explained elsewhere. ${ }^{12}$ 


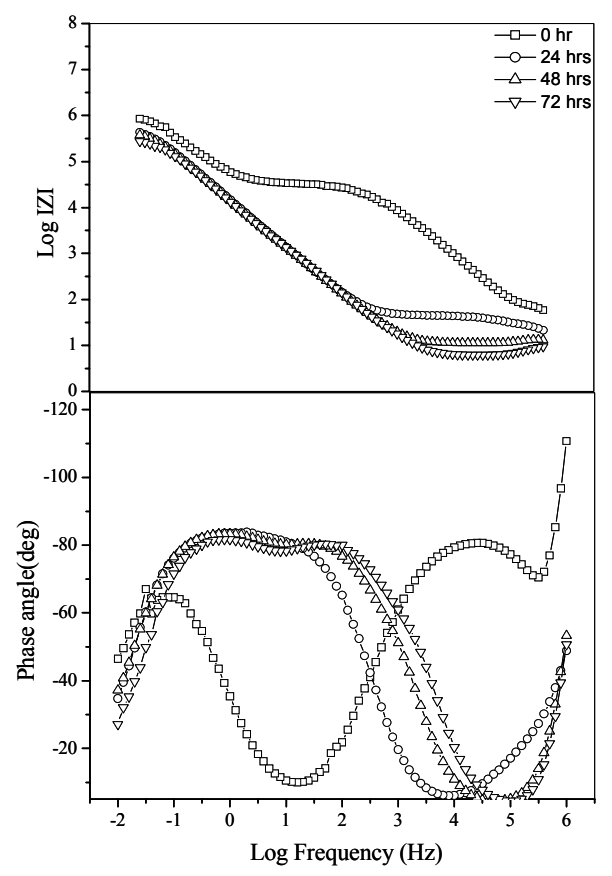

a

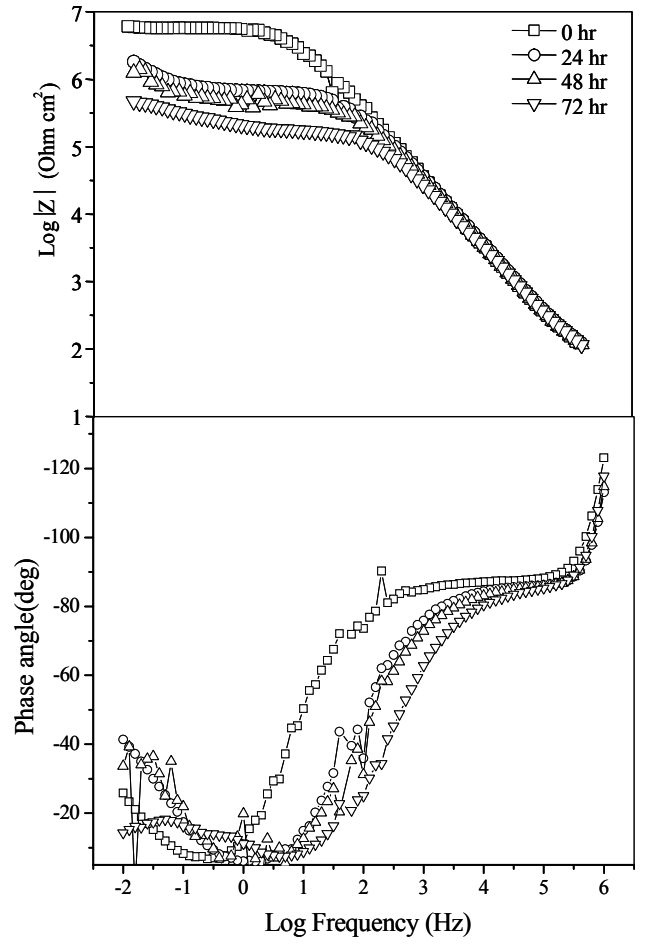

b

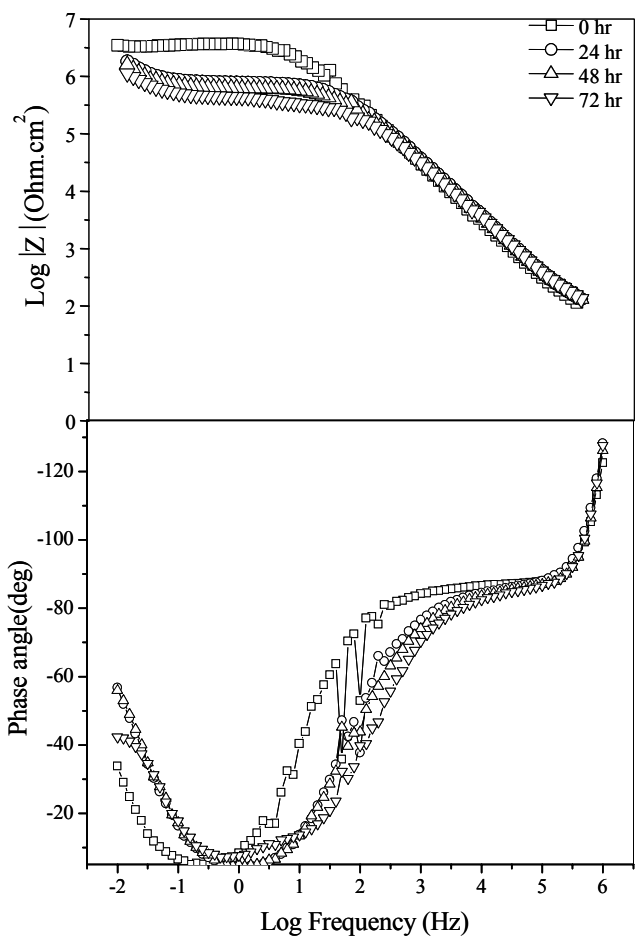

$\mathrm{C}$

Figure 5. Bode plot for coating exposed to dilute Harrison's from 0 to $72 \mathrm{hrs}$ (a) MAPTMS, (b)MAPTMS/Zr/MAAH, (c)MAPTMS/Zr/AcOH 
Dilute Harrisons was used as the electrolyte as it is considered to closely imitate the atmospheric environment for aircraft. ${ }^{13,14}$

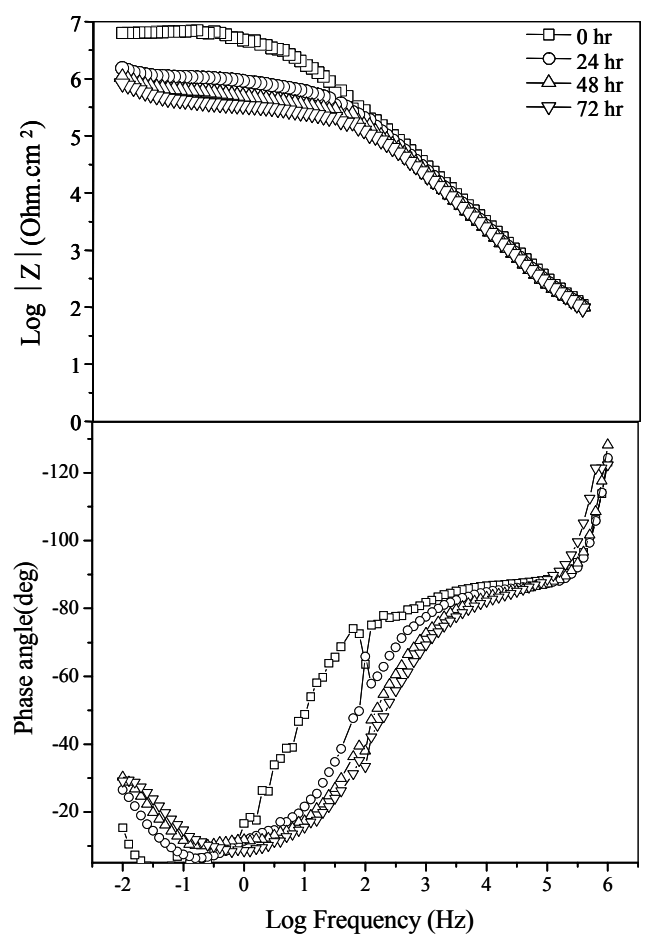

a

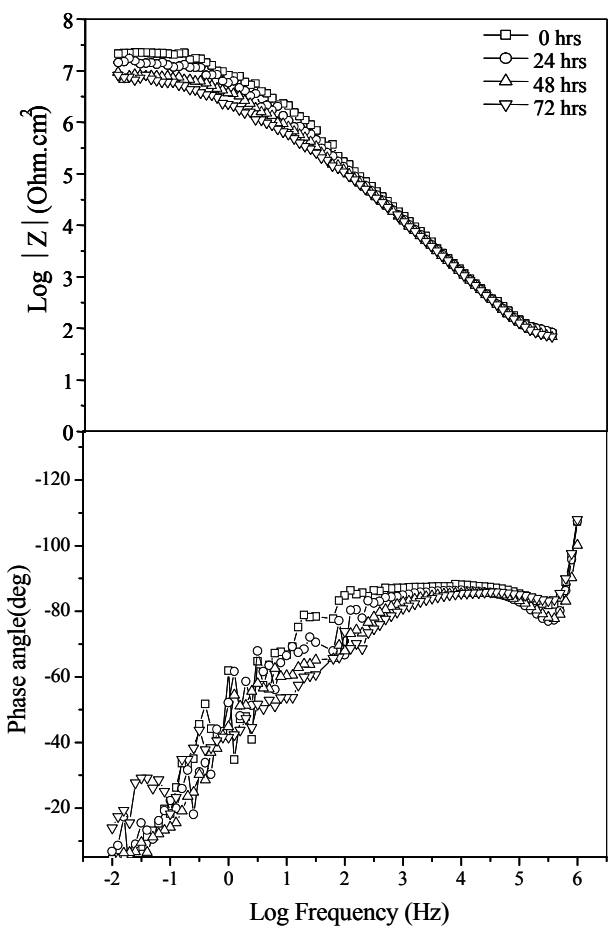

$\mathrm{b}$

Figure 6. Bode plot for coating exposed to dilute Harrison's from 0 to 72 hrs (a) MAPTMS/Zr/IBA, (b) MAPTMS/Zr/DABA.

EIS data are displayed in terms of Bode plots where the impedance magnitude and phases are plotted as function of frequency. The Bode plots for MAPTMS, acid modified coatings are shown in Fig. 5 and Fig. 6 while the other coatings are shown in Fig. 7. The coatings based on organic acids and acac perform similarly with $|\mathrm{Z}|$ plateau $\left(|\mathrm{Z}| \approx 10^{7}\right.$ $\Omega \mathrm{cm}^{2}$ ) at low frequency $(<1 \mathrm{~Hz})$, typically indicative of non porous surface. The apparent drop in impedance performance for MAPTMS/Zr/Bipy alone for $0 \mathrm{hr}$ of immersion can be interpreted as rapid electrolyte ingress and possible interface corrosion ( $\varphi$ increased to $-60^{\circ}$ at $10^{-1} \mathrm{~Hz}$ ). In contrast MAPTMS/Zr/DABA, MAPTMS/Zr/MAAH and MAPTMS/Zr/AcOH performed best, maintaining high impedance with a minimal phase lag $\left(\varphi\right.$ remaining below $-20^{\circ}$ at $10^{-2} \mathrm{~Hz}$ ). The phase angle decreases from $-85^{\circ}$ at high frequencies to a value close to $-60^{\circ}$ at intermediate frequencies and it reaches a minimum at a frequency close to $10^{0} \mathrm{~Hz}$ for the acid chelated coatings. The effect of DABA is noteworthy as no corrosion product is detected at low frequency. This would indicate that the nature of DABA may play a role in passivating the alloy surface, most likely through weak hydrogen bond interactions of the amine group with copper intermetallics. For MAPTMS/Zr/acac and MAPTMS/Zr/Bipy coatings, the phase angle decreases from $-85^{\circ}$ at high frequencies to value close to $-40^{\circ}$ at intermediate frequencies where it then reaches a minimum at a frequency close to $10^{2} \mathrm{~Hz}$ which indicates coating degradation. 
As with the DSC study, the acid chelated systems appear to be the most stable and resistant to corrosion product formation.

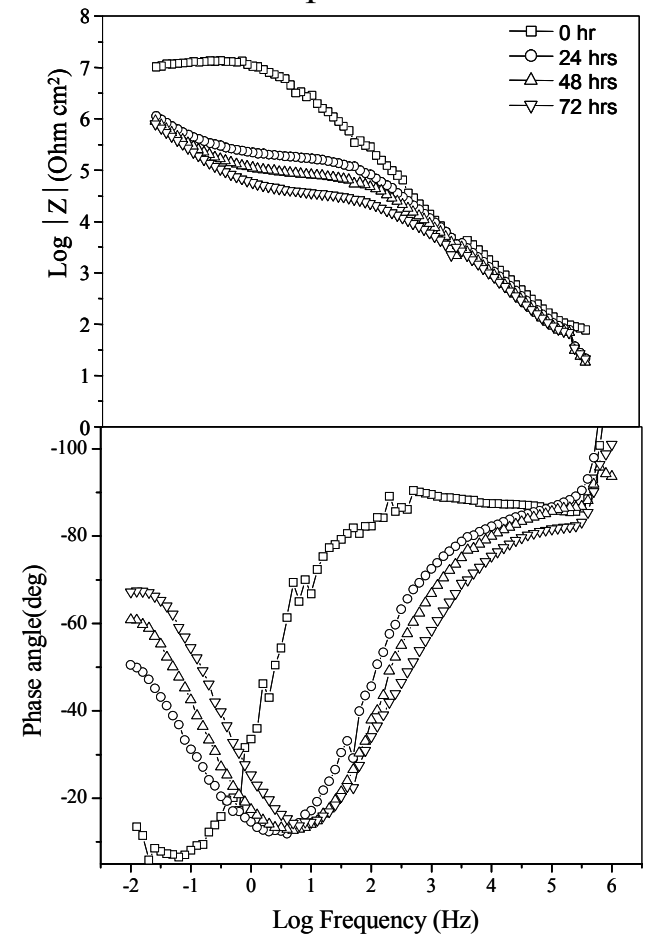

(a)

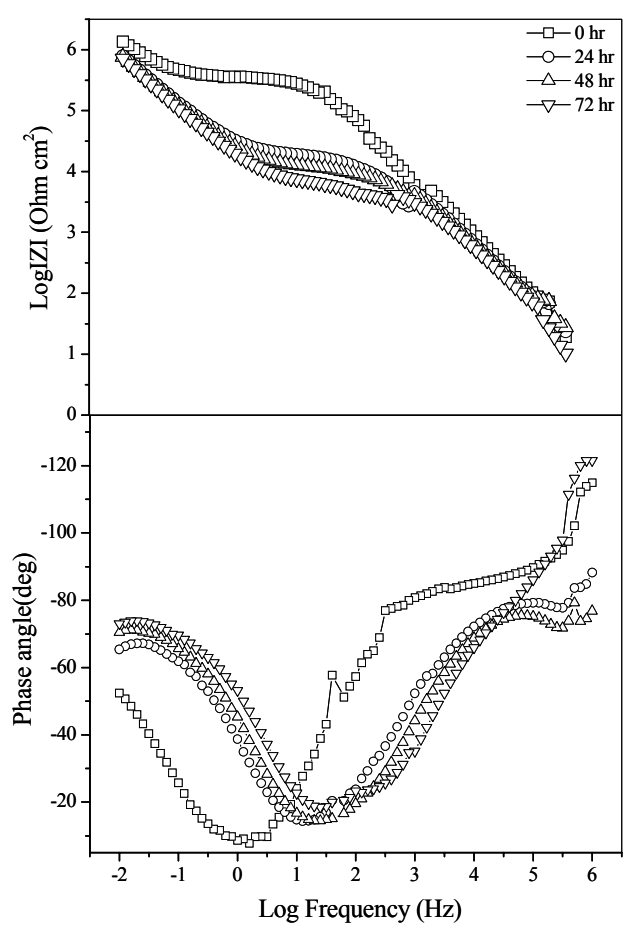

(b)

Figure 7. Bode plot for coating exposed to dilute Harrison's from 0 to $72 \mathrm{hrs}$ (a) MAPTMS/Zr/acac, (b) MAPTMS/Zr/Bipy.

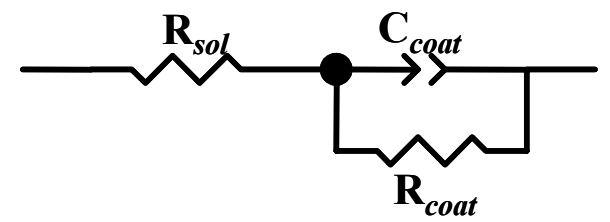

a

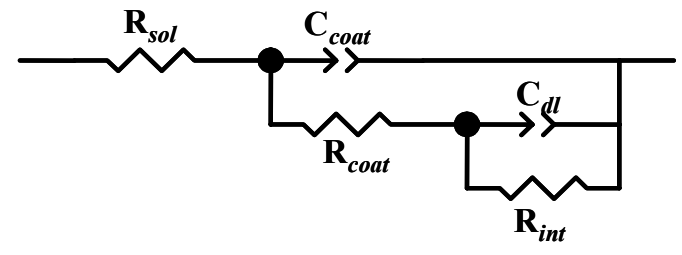

B

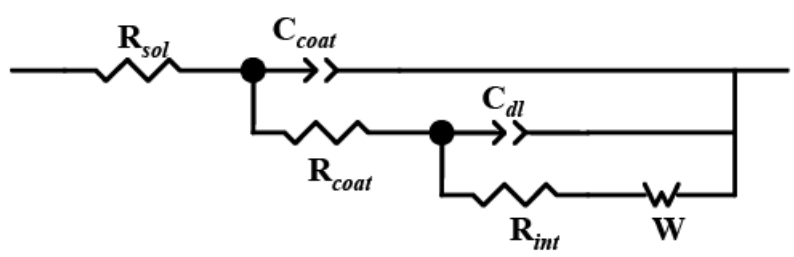

$\mathrm{C}$

Figure 8. Equivalent circuits used to numerically fit the Bode plots 
For explaining the EIS response, an equivalent circuit model illustrated at Fig. 8 (a) can be used to describe the behaviour of the sol gel coating with no pores at the initial stage of immersion. Over time the coating/electrolyte interface will change and it is therefore necessary to use different equivalent circuits at subsequent time intervals. Therefore Fig. 8 (b) \& (c) describes the behaviour of the system between 24 and $72 \mathrm{hrs}$ of immersion. The constant phase element (CPE) was used as the capacitive element in all fittings when the phase angle of the capacitor is different from $-90^{\circ}$. The parameter $\mathrm{R}_{s o l}$ corresponds to the solution resistance, $\mathrm{R}_{\text {coat }}$ is the coating resistance, $\mathrm{C}_{\text {coat }}$ is the coating capacitance, $\mathrm{R}_{\text {int }}$ is the resistance at coating/alloy interface. $\mathrm{C}_{d l}$ accounts for the double layer capacitance and $\mathrm{W}$ is the Warburg element which accounts for the diffusion of oxygen and water into the coating. With the onset of electrolyte penetration, pathways develop within the coating, thereby reducing the coating resistance. The increase of the immersion time leads to coating degradation and thereby an increase in the coating capacitance $\left(\mathrm{C}_{\text {coat }}\right)$. On interaction with the alloy surface, the electrolyte initiates corrosion which results in a product forming at the interface. This phenomenon is then represented as an additional element (see Fig. 8 (c)) with an interfacial resistance and double layer capacitance being detected at low frequencies $(<1 \mathrm{~Hz})$. Fig. 9 shows the change in $\mathrm{C}_{\text {coat }}$ with time when exposed to dilute Harrison. It is well known that an increase of $\mathrm{C}_{\text {coat }}$ during exposure implies coating degradation. ${ }^{15}$ The coating capacitance of MAPTMS exhibits significantly faster growth due to the ingress of water through the coatings porous topography of MAPTMS. For all other ligand modified coatings there shows an increase in $\mathrm{C}_{\text {coat }}$. However MAPTMS/Zr/Bipy and MAPTMS/Zr/acac exhibits significantly changes over time, which may be due to the increase in dielectric constant of the coating. The calculated electrochemical parameters of the sol-gel coatings, based on a linear regression method, are given in Table III.

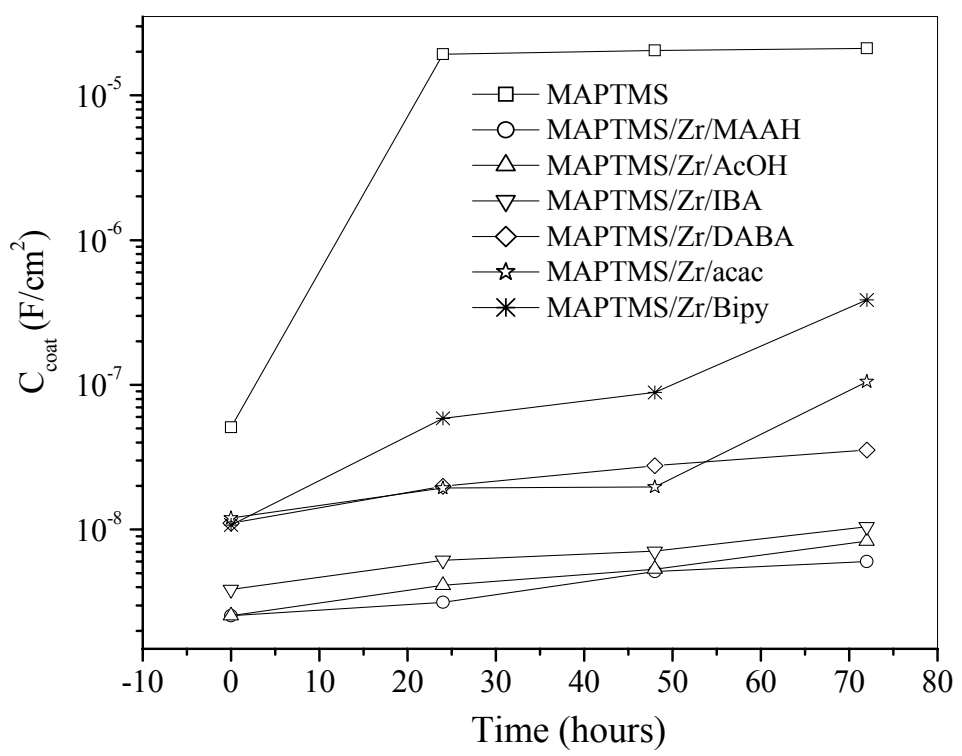

Figure 9: Evolution of the capacitance for the sol-gel coatings during immersion dilute Harrison's solution at different intervals. 


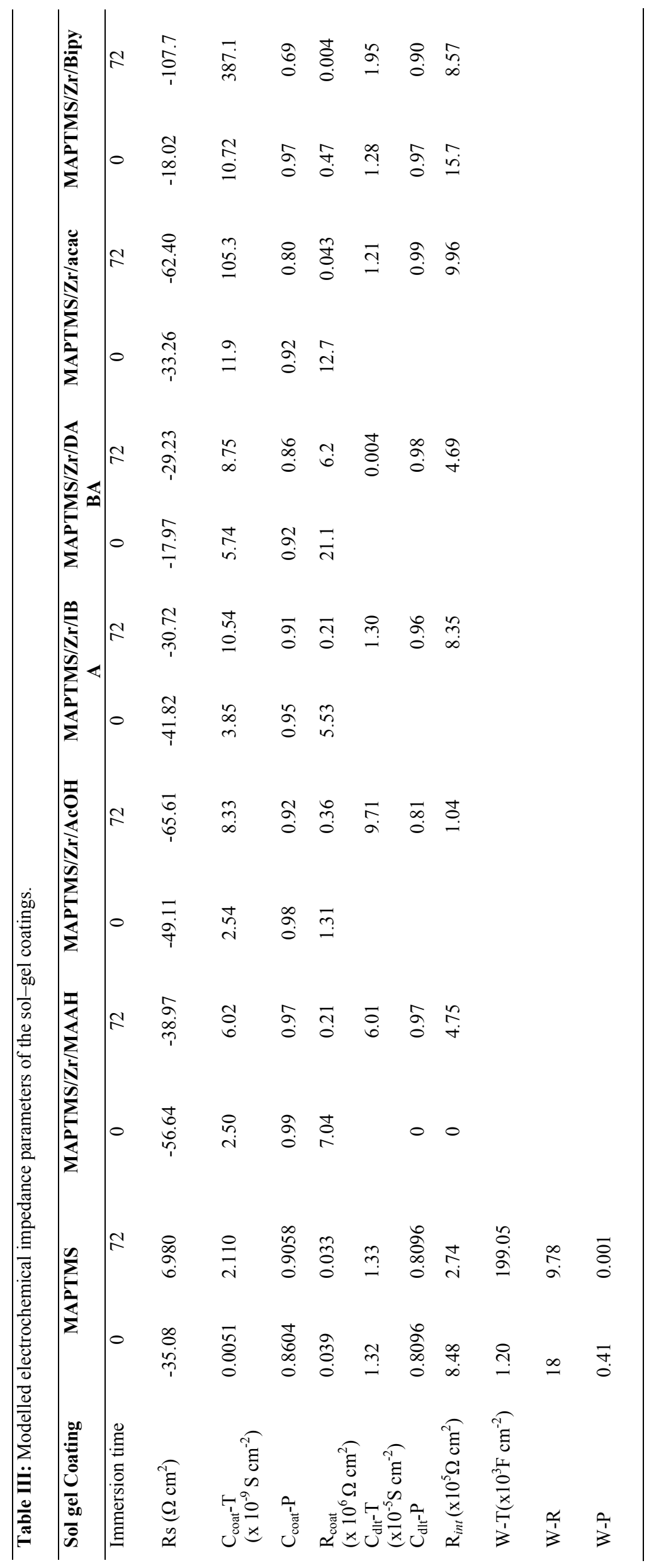




\section{Neutral Salt Spray Test}

Fig. 10 shows the salt spray results for all coatings after $168 \mathrm{hr}$ exposure except MAPTMS (48hr). MAPTMS coating heavily corrode after $48 \mathrm{hr}$ of inspection and no rating was given. The rating for MAPTMS was not given as coating degraded completely within 48 hours of salt spray exposure. The coatings based on MAPTMS/Zr/MAAH, MAPTMS/Zr/AcOH and MAPTMS/Zr/DABA performed best, corroding only along the scribe with little pitting observed. The same order of performance as seen with DSC, EIS and PDS was observed, whereby MAPTMS/Zr/IBA coating outperformed the MAPTMS/Zr/acac and MAPTMS/Zr/Bipy equivalents. Pitting was observed for the MAPTMS/Zr/IBA coating, to a greater extent on the MAPTMS/Zr/acac coating with extensive corrosion product present on the MAPTMS/Zr/Bipy surface. The performances of ligand modified coatings are given in Table IV

\begin{tabular}{lccc}
\hline \multicolumn{4}{c}{ Table IV: Rating of the failure in scribe and unscribed area as per ASTM D1654 } \\
\hline Sol-gel coating & $\begin{array}{l}\text { Number of hours } \\
\text { exposed to NSS }\end{array}$ & $\begin{array}{c}\text { Rating of scribed } \\
\text { area }\end{array}$ & $\begin{array}{c}\text { Rating of un scribed } \\
\text { area }\end{array}$ \\
MAPTMS & 48 & 2 & 2 \\
MAPTMS/Zr/MAAH & 168 & 4 & 7 \\
MAPTMS/Zr/AcOH & 168 & 5 & 8 \\
MAPTMS/Zr/IBA & 168 & 2 & 6 \\
MAPTMS/Zr/DABA & 168 & 8 & 8 \\
MAPTMS/Zr/acac & 168 & 3 & 3 \\
MAPTMS/Zr/Bipy & 168 & 2 & 2 \\
\hline
\end{tabular}



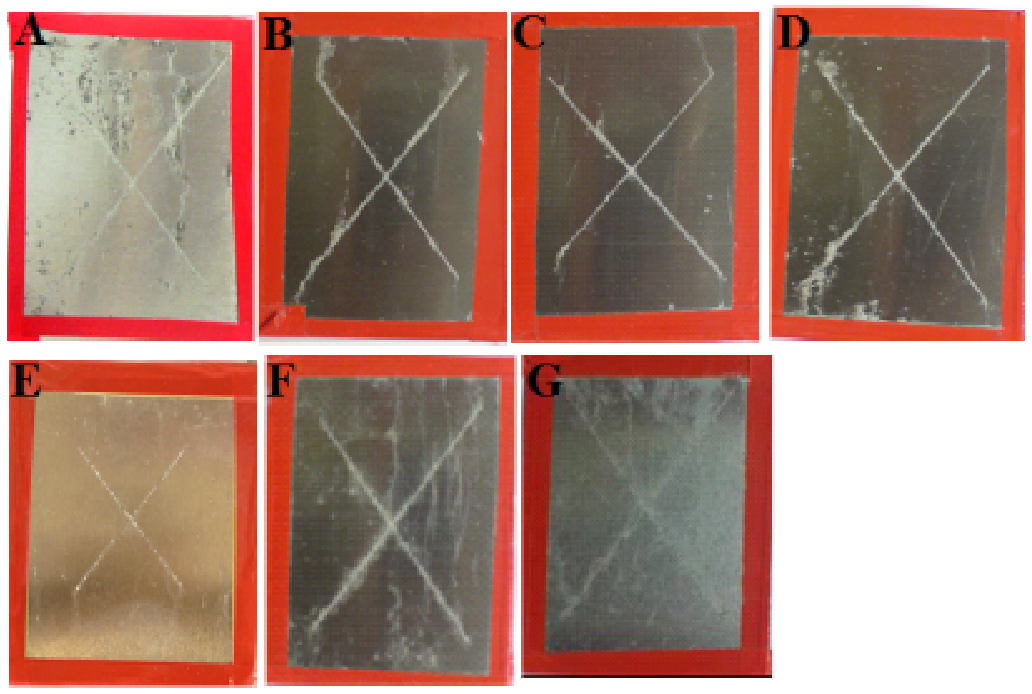

Figure 10: Neutral Salt spray results for different coatings (A)MAPTMS exposed to $48 \mathrm{hrs,} \mathrm{(B)}$ MAPTMS/Zr/MAAH, (C) MAPTMS/Zr/AcOH, (D) MAPTMS/Zr/IBA, (E) MAPTMS/Zr/DABA, (F) MAPTMS/Zr/acac, (G) MAPTMS/Zr/Bipy on AA 2024-T3 exposed for 1 week 


\section{Conclusion}

The MAPTMS sol-gels modified using various ligands were investigated as surface coatings to protect the aerospace alloy AA2024-T3 from corrosion. The electrochemical studies and neutral salt spray results indicated that the zirconium nanoparticles significantly improved the corrosion protection performance of the ormosil coating. The performance of the coatings based on certain acid chelates was seen to be providing the best corrosion properties when compared to non acid chelates. This result was confirmed by thermal, electrochemical and neutral salt spray studies. The improved performance of the acid modified ligands may be due the formation of much smaller size $\mathrm{ZrO}_{2}$ nanoparticles during the hydrolysis and condensation process. DLS and AFM images confirmed the presence of relatively smaller particles within acid modified hybrid coating surfaces in comparison to the other coatings which possessed much larger agglomerates that may impede the formation of a dense polymeric network thereby allowing the ingress of electrolyte to promote corrosion. Of particular note is the ability of diaminobenzoic acid to provide improved performance due the ability of the amine functionality to potentially passivate the metal surface.

\section{Acknowledgments}

The authors would like to thank Enterprise Ireland for financial support through the Dualion project (CFTD/05/306) and provision of CREST Centre funding through the ARE programme. The authors also thank Dr. Luke O'Neil of the Focas Institute for AFM assistance.

\section{References}

1. U. Schubert, J. Mater. Chem., 15, 3701 (2005).

2 G. Phillip and H. Schmidt, U.S Patent US 4746366, (1988).

3. C. Sanchez, J. Livage, M. Henry and F. Babonneau, J. Non-Cryst. Solids, 100, 65 (1988).

4. U. Schubert, J. Sol-Gel Sci. Technol., 26, 47 (2003).

5. M. Chatry. M. Henry, M. In, C. Sanchez, J. Livage, J. Sol-Gel Sci. Technol., 1, 233 (1994).

6. H. Hayashi, H. Suzuki, S. Kaneko, J. Sol-Gel Sci. Technol., 12, 87 (1998).

7. S. K. Poznyak, M. L. Zheludkevich, D. Raps, F. Gammel, K. A. Yasakau and M. G. S. Ferreira, Prog. Org. Coat., 62, 226 (2008).

8. M. F. Montemor, W. Trabelsi, M. Zheludevich and M. G. S. Ferreira, Prog. Org. Coat., 57, 67 (2006).

9. M. L. Zheludkevich, K. A. Yasakau, S. K. Poznyak and M. G. S. Ferreira, Corros. Sci., 47, 3368 (2005).

10. M. Kendig, S. Jeanjaquet, R. Addison and J. Waldrop, Surf. Coat. Technol., 140, 58 (2001).

11. V. Barranco, S. Feliu Jr. and S. Feliu, Corros. Sci., 46, 2203 (2004). 
12. M.L. Zheludkevich, R. Serra, M.F. Montemor, K.A. Yasakau, I.M. Miranda Salvado and M.G.S. Ferreira, Electrochim. Acta, 51, 208 (2005).

13. A.M. Simoes, D. Battocchi, D.E. Tallman and G.P. Bierwagen, Corros. Sci. 49, 3838 (2007).

14. R. Twite, S. Balbyshev and G. Bierwagen, in: S.R. Taylor, H.G. Isaacs, E.W. Drooman (Eds.), Proceedings of Symposium on Environmentally Acceptable Inhibitors and Coatings, Special Publication of the Electro-Chemical Society, 9516, 202 (1997).

15. A. Amirudin and D. Thierry, Prog. Org. Coat. 26, 1, (1995). 